\title{
A vivência de casais inférteis diante de tentativas inexitosas de reprodução assistida
}

\author{
The Experience of Infertile Couples Facing Unsuccessful Assisted \\ Reproductive fttempts \\ La experiencia de parejas infértiles delante de intentos infructuosos \\ de reproducción asistida
}

\author{
Patrícia Pinheiro Marques* \\ Normanda Araujo de Morais* \\ *Universidade de Fortaleza (Unifor), Ceará, Brasil.
}

Doi: http://dx.doi.org/10.12804/revistas.urosario.edu.co/apl/a.4315

\section{Resumo}

\begin{abstract}
Esse artigo tem como objetivo compreender a vivência de casais inférteis diante de tentativas inexitosas de reprodução assistida (RA). Especificamente, busca-se descrever os sentimentos mais frequentes durante as tentativas inexitosas e os possíveis impactos destas tentativas. Realizaram-se estudos de casos múltiplos com 3 casais heterossexuais (38-45 anos de idade), a partir de entrevistas individuais com cada membro da díade. A análise de conteúdo evidenciou um forte investimento subjetivo para a chegada do filho e que a repetição dos tratamentos influenciou no aumento do sofrimento dos cônjuges, trazendo consequências para a sexualidade e comunicação dos casais. A dimensão financeira, por outro lado, não sofreu grandes impactos.
\end{abstract}

Os casais demonstraram forte vínculo emocional, permanecendo juntos diante das tentativas inexitosas e na busca de novas alternativas para a vivência da parentalidade. Conclui-se ressaltando a importância do apoio psicológico (antes, durante e após a realização dos ciclos) aos casais submetidos aos procedimentos de RA. Palavras-chave: infertilidade, casais, reprodução assistida.

\section{fbstract}

This article aims to understand the experience of infertile couples facing lack of success on assisted reproduction (AR) attempts. It describes, specifically, the most common feelings during unsuccessful attempts and possible impacts of these attempts. There were multiple case

* Patrícia Pinheiro Marques, Normanda Araujo de Morais, Programa de Pós-Graduação em Psicologia, Universidade de Fortaleza (Unifor), Ceará, Brasil.

Correspondência a respeito deste artigo deve ser endereçada para Normanda Araujo de Morais, Universidade de Fortaleza, Programa de Pós-Graduação em Psicologia, Avenida Washington Soares, 1321, Edson Queiroz. CEP: 60.811-905. Fortaleza-CE, Brasil. Correio eletrônico: normandaaraujo@gmail.com

Cómo citar este artículo: Marques, P. P. \& Morais, N.A. (2018). A vivência de casais inférteis diante de tentativas inexitosas de reprodução assistida. Avances en Psicología Latinoamericana, 36(2), 299-314. DOI: http://dx.doi. org/10.12804/revistas.urosario.edu.co/apl/a.4315 
studies with three heterosexual couples (38-45 years old), from individual interviews with each member of the dyad. The content analysis showed a strong subjective investment of many kinds for the arrival of the child and that the repetition of the treatments influenced the increased suffering of the spouses, bringing consequences for the couples' sexuality and communication. The financial dimension, on the other hand, did not suffer major impacts. Couples have shown strong emotional bonds, staying together under the unsuccessful attempts and in the search for new alternatives for the parenting experience. As a conclusion of this study we stress the importance of psychological support (before, during and after the realization of cycles) to couples undergoing procedures for AR.

Keywords: infertility, couples, assisted reproduction.

\section{Resumen}

Este artículo tuvo como objetivo comprender la experiencia de parejas infértiles que enfrentan intentos infructuosos de reproducción asistida (RA). Específicamente se buscó indentificar los sentimientos más frecuentes durante los intentos infructuosos y comprender los posibles impactos de estos intentos. Se realizaron estudios de caso múltiples con tres parejas heterosexuales (38-45 años de edad), a partir de entrevistas individuales con cada miembro de la pareja. El análisis de contenido evidenció una fuerte inversión subjetiva en la llegada del hijo, y que la repetición de los tratamientos influyó en el sufrimiento de los conyugues, con consecuencias en la sexualidad y la comunicación de las parejas. La dimensión financiera, por otro lado, no sufrió un gran impacto. Las parejas demostraron un fuerte vínculo emcional, permaneciendo juntas frente a los intentos infructuosos y en la búsqueda de nuevas alternativas para vivenciar la parentalidad. Se concluye destacando la importancia del apoyo psicológico (antes, durante y después de los ciclos) a las parejas sometidas a los procedimientos de (RA).

Palabras clave: infertilidad, parejas, reproducción asistida.
A infertilidade é compreendida como uma doença do sistema reprodutivo, caracterizada pela falha de se obter gravidez clínica após 12 meses ou mais de coito regular desprotegido (Corrêa, Vizzotto \& Cury, 2007; Gorayeb, Borsari, Gomes, Romão \& Shuhama, 2009; Van der Poel, 2012). Esta possui causas multideterminadas, como por exemplo: fatores masculinos e femininos; aumento da idade na decisão da maternidade e postergação da concepção; doenças sexualmente transmissíveis e inflamatórias do aparelho reprodutor masculino e feminino; hábitos de vida associados à sedentaridade, obesidade, tabagismo; e consumo excessivo de álcool ou de drogas ilícitas (Moura, Souza \& Scheffer, 2009).

Embora as taxas de prevalências sejam uma tarefa difícil de afirmar com precisão (Lopes \& Pinto, 2012; Van der Poel, 2012), estima-se que a infertilidade involuntária atinja 80 milhões de casais em todo o mundo e de 4 a 7 milhões de mulheres no Brasil (Gradvohl, Osis \& Makuch, 2013). Trata-se de um fenômeno que aumenta com a idade e atinge um em cada quatro casais com mais de 35 anos (Arruda \& Lima, 2012). Tais dados vêm despertando preocupação crescente e despertando a atenção de muitos pesquisadores.

A complexidade envolvida na temática da infertilidade implica a necessidade de intervenções que incluam as dimensões emocionais e que considerem o contexto ambiental no qual a mesma está inserida (Farinati, Rigoni \& Müller, 2006). Dessa forma, entende-se que o tratamento deve abranger muito mais que enfermidades, mas tratar sujeitos, escutando seu sofrimento para além de uma dimensão exclusivamente orgânica e biologicista.

A infertilidade, nessa perspectiva, é ainda mais pungente na busca de um entendimento interdisciplinar, pois se destacam múltiplos processos que alcançam as esferas sociais e psicológicas, além dos aspectos biológicos que nela estão envolvidos. Os casais que atravessam uma problemática dessa ordem demandam um olhar do médico, do profissional de saúde mental, do apoio social e de todos 
os demais profissionais que estão comprometidos com seu tratamento. Quando um problema com esta complexidade é diagnosticado, é preciso compreender o casal de maneira ampla e considerar que diferentes fatores estão interrelacionados (Farinati et al., 2006).

Diante dessa ampla conjuntura, sabe-se que as realidades conjugais inseridas no contexto de infertilidade são atravessadas pelas tecnologias reprodutivas e fazem parte de um contexto no qual os saberes biomédicos imperam, acarretando transformações subjetivas e sociais incontestáveis na contemporaneidade. A consequente normatização do sujeito, de suas subjetividades e do social pela biotecnologia "exige reflexões não reducionistas e lineares, permitindo olhares polissêmicos acerca da complexidade envolvida, em termos subjetivos, no ato de ter filhos, de gerar descendentes" (Monteiro \& Teixeira, 2011, p. 98).

Tendo em vista o lugar hegemônico conferido à prole (Borsa \& Nunes, 2011; Carter \& McGoldrik, 1995; Monteiro \& Teixeira, 2011), a constatação da impossibilidade de tê-los costuma acarretar um processo de grande sofrimento às famílias. Nas últimas 3 décadas, por exemplo, um número crescente de pesquisas têm evidenciado o impacto que a falta involuntária de filhos pode causar (Farinati, 1996; Gorayeb et al., 2009; Silva \& Lopes, 2011).

No cenário das conjugalidades na contemporaneidade num contexto de infertilidade, a Reprodução Assistida (RA), através da tecnologia biomédica, representa auxílio e alternativa para os casais que não conseguem ter filhos. As indicações dessas técnicas dependem das causas de infertilidade diagnosticadas e devem ser utilizadas quando outras terapêuticas tenham se revelado ineficazes ou consideradas inapropriadas (Moura et al., 2009; CFM, 2013).

A jornada percorrida diante dos tratamentos de reprodução assistida pode ser uma experiência muito sofrida, uma vez que é um percurso com início, mas sem perspectiva concreta de final, pois a gravidez pode ocorrer logo no início das tentativas sem a ajuda de alguma técnica, assim como os casais podem experimentar várias tentativas, sem que ocorra a chegada do filho biológico (Lopes \& Pinto, 2012). Os casais que vivenciam tratamentos sem êxito, podem iniciar um processo de desespero por terem o seu filho biológico. Sabe-se que o mais estressante da realidade destes sujeitos, entre a infertilidade e os tratamentos, não são os procedimentos médicos em si, mas as experiências da tentativa com a sua posterior comprovação de insucesso, ou seja, a constatação da não gravidez (Lopes \& Pinto, 2012; Sydsjo, Ekholm, Wadsby, Kjellberg \& Sydsjo, 2005).

Neste sentido, verifica-se que alguns trabalhos têm se dedicado a compreender a relação entre as Técnicas de Reprodução Assistida (TRAs) e o relacionamento conjugal (Faria, Grieco \& Barros, 2012; Filetto \& Makuch, 2005; Gorayeb et al., 2009; Verberg et al., 2008). Estes trabalhos têm destacado alguns aspectos, tais como: as TRAs não oferecem muitas garantias de sucesso; um período prolongado de tratamento sem sucesso pode provocar desgaste na qualidade do tratamento, da vida conjugal e pessoal; os casais tornam-se emocionalmente envolvidos, antes e durante o tratamento; a relação entre a expectativa da gravidez e seu insucesso pode gerar frustração, desesperança, depressão, ansiedade e raiva; o abandono do tratamento está associado ao sofrimento psicológico; a decisão pela repetição de ciclo mostra a capacidade comunicacional entre os cônjuges, embora também possa gerar estresse e tensão; e, por fim, a conclusão de um ciclo sem sucesso, pode representar a interrupção no projeto de vida e mudanças nos planos relativos aos papéis socialmente esperados, podendo provocar isolamento social.

Estudos empíricos ainda verificam a existência de desgaste relacional num período prolongado acima de 4 anos de tratamento sem obtenção de sucesso, ou seja, a não ocorrência da gravidez. Constata-se um aumento de ansiedade e sintomas depressivos em mulheres após duas semanas do primeiro ciclo de fertilização in vitro (FIV) sem 
sucesso e ao longo de até um ano após a falha de um ciclo de FIV. $\mathrm{O}$ abandono do tratamento pode ocorrer desde o primeiro ciclo de FIV sem êxito, e a incidência tende a aumentar a cada ciclo sem sucesso, embora se comprove que a taxa de nascidos vivos cumulativos ocorra com três ou mais tentativas. Além disso, o abandono também está associado a um mau prognóstico e à incapacidade de continuidade devido ao custeio dos tratamentos (Filetto \& Makuch, 2005; Gorayeb et al., 2009; Verberg et al., 2008). Tais aspectos, por sua vez, ilustram a complexidade dos contextos social, econômico, emocional e relacional dos casais que vivenciam o problema de infertilidade e a sua jornada diante dos tratamentos de reprodução assistida.

Os estudos sobre os efeitos do fracasso dos tratamentos de reprodução assistida sobre os casais inférteis são escassos. Sydsjo et al. (2005) fizeram um estudo prospectivo de casais, na Suécia, na década de 1990, que se submeteram a tratamentos que falharam. Os efeitos do insucesso em longo prazo foram pesquisados por Filetto e Makuch (2005). Estas mesmas autoras também investigaram como mulheres e homens lidam com as vivências decorrentes do esforço e desgaste físico ao se submeterem à FIV sem obter sucesso (Makuch \& Filetto, 2010).

Por considerar os efeitos que os tratamentos de reprodução assistida sem êxito e suas repetições possam produzir sobre os casais que enfrentam a problemática da infertilidade, este artigo objetiva compreender as vivências de casais inférteis diante de tentativas inexitosas de reprodução assistida. Mais especificamente, buscar-se-á descrever os sentimentos mais frequentes diante das múltiplas tentativas inexitosas, e os possíveis impactos destas tentativas nas diferentes dimensões da vida dos casais entrevistados.

O "insucesso" nesse artigo está relacionado à constatação da não gravidez após Tratamentos de Reprodução Assistida (TRAs), e à ênfase sobre este tema decorre do interesse em aprofundar o conhecimento do universo destes casais e pelo fato da literatura enfocar muito mais nos casos de sucesso, ou seja, quando ocorre a gravidez e o nascimento do bebê, bem como a vivência da conjugalidade durante o tratamento; enquanto pouca atenção tem sido dada aos casos que não têm êxito.

Por isso, compreende-se que existe um terreno ainda muito fértil para o estudo de tratamentos de repetição e o efeito que os mesmos produzem sobre os casais com demandas de infertilidade. Espera-se que esta pesquisa possa ampliar o campo de estudos teóricos e de trabalhos empíricos que venham a contribuir para os procedimentos de avaliação, diagnóstico e tratamento no campo das conjugalidades que enfrentam a jornada dos tratamentos de TRAS e a difícil constatação do insucesso destes.

\section{Método}

\section{Delineamento}

Tratou-se de uma investigação qualitativa, de natureza exploratória e descritiva através do uso do delineamento de Estudo de Caso Múltiplo (Yin, 2010). Esse delineamento visa à investigação de um caso específico (único ou múltiplo), o qual deve ser bem delimitado, contextualizado em tempo e lugar para que se possa realizar uma busca circunstanciada de informações. A preocupação não se pauta em analisar o caso em si como algo à parte, mas no que ele representa dentro e a partir do todo, enfatizando a multiplicidade de dimensões do problema (Ventura, 2007).

Os tipos de estudos de caso têm como foco uma unidade, ou seja, um indivíduo, e caracteriza -se como um único caso e singular, ou múltiplo, em que até vários casos podem ser conduzidos simultaneamente (Yin, 2010; Ventura, 2007). O presente estudo caracteriza-se como um estudo de caso múltiplo, pois tendo em vista a compreensão da vivência de casais inférteis numa realidade em que os tratamentos de reprodução assistida não 
obtiveram êxito, abrangeu mais de uma unidade conjugal. Todos os cônjuges foram entrevistados e não se perdeu a perspectiva relacional ante as especificidades das conjugalidades, bem como aos vários contextos implicados.

\section{Participantes}

Participaram 3 casais, os quais se submeteram a no mínimo duas tentativas inexitosas de Reprodução Assistida (RA) para tratamento da infertilidade. Tal número de tentativas justifica-se na literatura, a qual tende a descrever um número médio de 4 tentativas cumulativas para os casais com sucesso (Filetto \& Makuch, 2005; Sydsjo et al., 2005; Verberg et al., 2008). A escolha por duas tentativas de insucesso ocorreu pelo fato do acesso aos casais nesse perfil ser restrito, e em virtude das desistências aos convites que poderiam ocorrer, fato que poderia se tornar ainda mais complicado se ampliadas para três as tentativas de insucesso. A decisão pela escolha de três casais ocorreu em virtude do critério de saturação dos dados, uma vez que se percebeu na terceira entrevista que os conteúdos já se repetiam.

No que se refere à caracterização sociodemográfica dos participantes, verificou-se que a média de idade dos participantes foi de 40 anos, variando de 38-45 anos. Os 3 casais entrevistados eram cearenses: um residente da capital; outro casal residia na região metropolitana de Fortaleza; e um casal tinha domicílio na região norte do estado. 2 casais realizaram o tratamento em clínicas privadas e 1 casal estava efetuando o tratamento no Sistema Único de Saúde (SUS) no momento da realização da pesquisa. A escolha por um casal que se submeteu ao tratamento pelo SUS diz respeito à tentativa de escutar um público de perfil socioeconômico diferenciado, que diante da infertilidade e do desejo de ter filhos, recorre ao sistema público para concretização do seu sonho; fato que é bem diferente da maioria dos casais inférteis, que tendem a acessar majoritariamente clínicas particulares de RA.

\section{Instrumento}

Foi utilizado um roteiro de entrevista semiestruturada, desenvolvida especialmente para este estudo pelas autoras desse artigo. $\mathrm{O}$ roteiro foi composto por 5 temas centrais (relacionamento conjugal, diagnóstico de infertilidade, tratamento, estratégias para realização do desejo de ter filhos e rede de apoio), totalizando 10 questões.

\section{Procedimentos de coleta de dados}

Os participantes foram recrutados por conveniência e através da rede de contatos da primeira autora desse artigo. Em seguida, através do método snowball ("bola de neve"), chegou-se ao segundo e terceiro casal. Optou-se por essa estratégia, uma vez que o acesso às clínicas de tratamento para reprodução assistida é restrito, devido ao sigilo médico.

A pesquisa consistiu na realização das entrevistas individualmente, com cada integrante da díade conjugal. Os cônjuges participaram separadamente, em dias diferentes, para garantir o espaço individual da díade quanto às suas formas pessoais de expressão. As entrevistas foram realizadas durante um encontro e tiveram a duração média de 50 minutos. Após a identificação dos casais, foi realizado um primeiro contato por telefone com um dos cônjuges e explicou-se o teor da pesquisa. Um segundo contato por telefone ocorreu em virtude da resposta do outro cônjuge, visto que ambos precisariam conceder a participação, bem como ficar ciente de que as entrevistas ocorreriam separadamente e em dias diferentes. O terceiro contato já se deu no local escolhido pelos participantes. No caso, todos sugeriram suas residências. Todas as entrevistas foram conduzidas pela primeira autora, gravadas e transcritas posteriormente. 


\section{Procedimentos de análise de dados}

No tratamento dos dados coletados, seguiu-se à proposta da Análise de Conteúdo (Bardin, 1977/1979) - p. 304 e as categorias temáticas foram elaboradas a posteriori quando da análise das entrevistas. A discussão dos dados, por sua vez, teve como base estudos anteriores publicados na área.

\section{Procedimentos éticos}

Essa pesquisa recebeu aprovação do Comitê de Ética em Pesquisa da Universidade de Fortaleza (Parecer 715.771), e atendeu a todas as diretrizes do Conselho Nacional de Saúde para pesquisa envolvendo seres humanos (CFM, 2012). Todos os participantes foram informados acerca dos objetivos da pesquisa, riscos e benefícios e consentiram em assinar o Termo de Consentimento Livre e Esclarecido (TCLE). Somente após, as entrevistas foram realizadas.

\section{Resultados e discussão}

Para preservar a identidade dos participantes, os casais serão identificados como Casal I, Casal II e Casal III. Os ciclos e tratamentos efetuados pelos casais, assim como uma maior caracterização dos participantes estão descritas na tabela 1 .

Dos casais entrevistados, todos os cônjuges dos Casais I e II tinham nível superior completo e empregos públicos estaduais e municipais. Estes fizeram os tratamentos na rede especializada privada para reprodução assistida. No Casal III, a esposa tinha nível superior completo, exercia atividade autônoma e o marido, o primeiro grau incompleto e exercia atividade laboral como auxiliar de direção. Eles estavam fazendo o tratamento na rede pública de saúde.

Nenhum dos casais tinha filhos biológicos do relacionamento atual, mas dois maridos (I e III) tinham filhos biológicos de relacionamentos anteriores. Apenas o Casal II não tinha filhos biológicos, mesmo de outros relacionamentos. Após tentativas inexitosas de tratamento, dois casais (I e II) optaram pela adoção, sendo que entre estes, o Casal I decidiu não mais ter filhos e interromperam os tratamentos de RA; enquanto o Casal II, mesmo após a adoção, deu continuidade aos tratamentos de RA. O Casal III estava na fase inicial dos tratamentos e a adoção, ou outra alternativa, não era uma opção até o momento das entrevistas.

Tabela 1

Caracterização dos participantes e dos tratamentos de reprodução assistida realizados

\begin{tabular}{|c|c|c|c|c|c|c|}
\hline \multirow[b]{2}{*}{ Casais } & \multicolumn{2}{|c|}{ I } & \multicolumn{2}{|c|}{ II } & \multicolumn{2}{|c|}{ III } \\
\hline & $\begin{array}{l}\text { Rosa } \\
\text { Pinho }\end{array}$ & $\begin{array}{l}43 \text { anos } \\
38 \text { anos }\end{array}$ & $\begin{array}{c}\text { Aurora } \\
\text { Oliveira }\end{array}$ & $\begin{array}{l}45 \text { anos } \\
41 \text { anos }\end{array}$ & $\begin{array}{l}\text { Margarida } \\
\text { Nogueira }\end{array}$ & $\begin{array}{l}40 \text { anos } \\
38 \text { anos }\end{array}$ \\
\hline Tempo de tratamento & \multicolumn{2}{|c|}{$\begin{array}{l}\text { Início: } 1 \text { ano após casamento } \\
\text { Duração: } 10 \text { anos }\end{array}$} & \multicolumn{2}{|c|}{$\begin{array}{l}\text { Início: } 5 \text { anos após casamento } \\
\text { Duração: } 2 \text { anos }\end{array}$} & \multicolumn{2}{|c|}{$\begin{array}{l}\text { Início: após casamento, a } 1 \\
\text { ano e meio }\end{array}$} \\
\hline \multirow{3}{*}{ Tipo de tratamento } & $\begin{array}{c}\text { Indução } \\
\text { de ovulação }\end{array}$ & 2 & \multicolumn{2}{|c|}{1} & \multicolumn{2}{|c|}{2} \\
\hline & $\begin{array}{l}\text { Inseminação } \\
\text { artificial (IA) }\end{array}$ & 1 & \multicolumn{2}{|c|}{2} & \multicolumn{2}{|c|}{-} \\
\hline & $\begin{array}{l}\text { Fertilização } \\
\text { in vitro (FIV) }\end{array}$ & 1 & \multicolumn{2}{|c|}{1} & & \\
\hline \multirow{2}{*}{ Filhos } & \multicolumn{2}{|c|}{1 biológico do marido } & \multicolumn{2}{|l|}{ - } & \multicolumn{2}{|c|}{1 biológico do marido } \\
\hline & \multicolumn{2}{|l|}{1 adoção do casal } & \multicolumn{2}{|c|}{1 adoção do casal } & \multicolumn{2}{|c|}{ Sem filhos do casal } \\
\hline
\end{tabular}


A análise de conteúdo das entrevistas gerou duas categorias temáticas: 1) vivência emocional e sentimentos marcantes dos tratamentos inexitosos; e 2) impactos dos tratamentos inexitosos sobre a vida dos casais.

\section{Vivência emocional e sentimentos marcantes dos tratamentos inexitosos}

Ao relatarem a vivência emocional e sentimentos marcantes dos processos de tratamento inexitosos, as esposas mencionaram tratar-se de lembranças muito doloridas, o pior momento da vida e que houve, inclusive, bloqueio de lembranças dos períodos de tratamento. Esse tendeu a ser descrito a partir de palavras/expressões muito negativas, como "impacto psicológico, trauma, tristeza, ansiedade, sofrimento, desespero, abalo, recolhimento, isolamento, desamparo universal, estar à flor da pele e pressão social". Tais descrições são mencionadas anteriormente na literatura. Farinati, Rigoni e Muller (2006), por exemplo, afirmam que o caráter estressante dos procedimentos do tratamento de infertilidade gera intenso desgaste pessoal e conjugal e a vivência da incapacidade de gerar filhos pode ser registrada como uma experiência de dilaceração biográfica. Lopes e Pinto (2012), por sua vez, afirmam que a vivência dos contextos de infertilidade pode encarnar acontecimentos indutores de estresse e funcionar como um risco de desorganização emocional.

Expectativa, angústia, frustração, tristeza e revolta foram sentimentos vivenciados no intervalo entre fazer o procedimento e a confirmação do resultado negativo. Essa perspectiva pode ser observada pelas Esposas I e II. Os trechos a seguir ilustram:

Constatar a chegada da menstruação foi horrível, momento muito forte, quase entrei em depressão: 'Meu Deus, por que comigo?' [...] eu comecei tipo a me revoltar, né? E eu me tranquei todinha em casa. Deixei as luzes apagadas e tudo.
E eu comecei a chorar, eu chorei tanto que eu rolei da cama no chão. (Esposa I referindo-se à sua terceira tentativa de gravidez que ocorreu através da Inseminação Artificial).

A Esposa II refere sobre os tratamentos de reprodução assistida: "Não faria aquele tratamento de novo, nem que me dessem de graça!" (Esposa II). De forma semelhante, seu marido também mencionou o sofrimento por ter passado pelos processos de confirmações negativas dos exames. Farinati (1996) relata estudos sobre a relação do estresse em casais submetidos à reprodução assistida. A autora referiu que um dos momentos de maior tensão emocional estava associado a aguardar o resultado do procedimento, ou seja, a ocorrência ou não da gravidez. Os outros dois momentos seriam o da implantação do embrião e o dia da coleta dos óvulos.

Diferentemente das participantes anteriormente citadas, a Esposa III mostrou ser positiva: "Sou positiva, pois acho que vou conseguir engravidar novamente, com a ajuda do tratamento". É importante observar que esta última encontrava-se na fase diagnóstica e inicial dos tratamentos, tendo feito, até o momento da entrevista, 2 ciclos com indutores de ovulação, o que explicaria uma visão mais positiva dos tratamentos. Esta técnica de indução de ovulação é considerada de menor complexidade no campo da reprodução assistida, ao passo que as Esposas I e II foram submetidas a outros tratamentos mais invasivos, como a Inseminação Artificial e a Fertilização in vitro, os quais requerem a utilização de medicações e uma rotina disciplinada de exames. Estes aspectos justificariam a tendência das descrições das vivências emocionais mais negativas por estas esposas. O fato do Casal III estar num processo inicial dos tratamentos explicaria uma visão mais positiva do processo. Makuch e Filetto (2010) relatam que homens e mulheres tendem a iniciar o tratamento com grandes expectativas de sucesso e pouco realistas em relação às possibilidades de 
um resultado negativo. Quando o procedimento fracassa, surgem vivências de tristeza, decepção e perda, fazendo com que passem a avaliar suas vidas de forma negativa.

A Esposa I relatou que o terceiro ciclo foi vivenciado como a pior tentativa, fazendo com que “[...] caísse na real!", e a Esposa II referiu que "[...] após cada perda pensava em continuar a vida e retomar o trabalho, embora internamente soubesse que não estava bem". Nos estudos de Makuch e Filetto (2010), as expectativas de grande sucesso vivenciadas no início do tratamento são, frequentemente, pouco realistas em relação às possibilidades de um resultado positivo, e quando o procedimento fracassa, surgem vivências de tristeza, decepção e perda, motivo pelo qual muitas mulheres e homens passam a avaliar suas vidas de forma negativa. Esse fato foi confirmado diante do que aconteceu com o Casal I, que na terceira tentativa (inseminação artificial) apostaram "todas as fichas", sendo a experiência de insucesso que mais provocou a vivência de arraso e desespero na esposa, e grande preocupação do marido quanto ao estado físico e emocional da companheira.

Sobre a vivência emocional, os maridos relataram "abatimento, frustração, ter encarado com mais naturalidade do que a esposa, fé na vinda do filho biológico, ansiedade pelo resultado dos tratamentos, ter jogado para o esquecimento a parte difícil, ter sido difícil receber negativas da vida e preocupação com a quantidade de medicações". Os Maridos I e II revelaram uma vivência de sofrimento e investimentos frustrados, demonstrando uma visão mais negativa dos tratamentos. $\mathrm{O}$ trecho a seguir ilustra a experiência do Marido II: “[...] muito difícil encarar sempre a negativa da vida [...] uma fase de muitos investimentos: investimento pessoal, de sentimento e financeiro". Para o Marido III, apesar da expectativa de que o tratamento solucionasse o problema, chegou a propor pela desistência do mesmo. Por outro lado, referiu que se mantinha imparcial e apoiava qualquer decisão realizada pela esposa, assim como também, mostrava-se disponível após as perdas sofridas. Faria et al. (2012) constatam que os homens tendem a expressar sentimentos relacionados a uma postura de suporte, apoio e equilíbrio. Enquanto Gorayeb et al. (2009), em estudos relativos aos tratamentos, revelaram a ocorrência de ambivalência como desesperança, tranquilidade e esperança.

Apesar do Marido I afirmar que precisava "ser a pessoa positiva da relação" para dar força à esposa, reconheceu que isso the trazia abatimento. Devido às expectativas sociais associadas ao papel masculino tradicional, os homens tendem a conter a sua reatividade emocional, assumindo uma postura estoica de suporte na relação, exercendo papel de protetor e fonte de apoio às suas parceiras, apresentando aparentemente um comprometimento menor do aspecto emocional (Faria et al., 2012; Gameiro, Silva \& Canavarro, 2008).

O Marido II relatou que o tratamento mexeu um pouco com ele, mas que o amor e o relacionamento foram mais fortes e deram forças para continuar os tratamentos. Faria et al. (2012) afirmam que os casais demonstram sentimento de luta no decorrer do tratamento e, quando não se obtém uma gestação no final do ciclo, eles fazem desse sentimento o alicerce para iniciar mais um ciclo em busca da realização do projeto parental.

Makuch e Filetto (2010) afirmam que os homens são preocupados com os efeitos colaterais acarretados pelos tratamentos, demonstrando e expressando maiores preocupações quanto ao que os medicamentos possam causar à saúde das parceiras. Vargas e Moás (2010) chamam atenção para as diferentes vivências de homens e de mulheres em situação de infertilidade. E Oriá e Ximenes (2004, por sua vez, destacam que os casais se agarram à fé com todas as suas forças, como um fator que auxiliaria na resolução do processo.

O quarto e último ciclo, no qual vivenciou a terceira perda, foi descrito pelo Marido II como "a pior experiência de todos os tratamentos!" e foi vivenciado "[...] como se tivessem perdido um filho". Os embriões carregam as características 
biológicas do casal, o que demonstra um tipo de vínculo, mesmo que ao nível microscópico (Oriá \& Ximenes, 2004). Viver o insucesso dos tratamentos pode ser quase semelhante à dor da morte, à morte do filho sonhado, da saúde reprodutiva (Muñoz, 2006), uma vivência análoga a um processo de luto (Lopes \& Pinto, 2012).

No entanto, o intenso sofrimento diante da descoberta da perda provocou "algo de libertação e de abertura pra viver plenamente o que pudesse vir [...]" (Marido II). A dor emocional, segundo Filetto e Makuch (2005) é, para alguns casais, a justificativa pela escolha do abandono do tratamento que fazem mesmo antes de completarem todas as possíveis opções terapêuticas. Entretanto, foi a partir dessa dolorosa experiência que, para o Marido II, ocorreu uma "plena abertura" para outras possibilidades, no caso, a adoção, possibilidade que relutava aderir.

Lopes e Pinto (2012) mencionam a existência de diversas fases associadas à vivência psicológica da infertilidade e que seriam análogas a um processo de luto, inerentes à perda de uma fertilidade que se esperava sem dificuldade. A fase de resolução estaria relacionada ao luto pelo filho genético e a focalização em outras possibilidades da vida, tais como a adoção ou a vida sem filhos. Para o Marido II, por exemplo, "Foi a partir desta experiência que propiciou a resolução da decisão pela adoção e entrei num consenso com minha esposa sobre a desistência do tratamento". Na fase de resolução delineia-se a perspectiva do fim do tratamento e na fase do legado estaria englobada a etapa derradeira do percurso do casal infértil, implicando no balanço da experiência de infertilidade, que "pode ter efeitos devastadores ou por outro lado, pode representar um forte caminho para a maturidade" (Lopes \& Pinto, 2012, p. 42).

A literatura mostra que a experiência do tratamento pode ser prejudicial ou benéfico, a depender de cada caso. Num ciclo que não seja bem sucedido, ou seja, não tenha ocorrido a gravidez, passar pelo processo pode ser benéfico para aqueles casais que tenham um objetivo claro e estejam de acordo em dar continuidade ao próximo passo, embora o desafio esteja em tomar novas decisões (Sydsjo et al., 2005). Estes mesmos autores destacam que os estudos vêm mostrando que o mais estressante sobre a infertilidade não são os procedimentos médicos em si, mas o fato de tentar engravidar e não haver o sucesso. Os dados encontrados nesta pesquisa também confirmam os achados dos referidos autores. Tanto os maridos I e II referiram desgaste e sofrimento experienciados durante a vivência dos sucessivos tratamentos. O Marido III não relatou a vivência de sofrimento. Esse dado pode ter relação ao fato do casal estar no processo inicial dos tratamentos.

As diferentes jornadas vivenciadas por estes três casais revelam os grandes desafios que todos passaram. Estes apresentaram profundos sofrimentos, mas também, expectativas quanto às respostas que os tratamentos de Reprodução Assistida pudessem proporcionar. Percebeu-se que as mulheres não se intimidaram ao falar de suas dores, frustrações e esperanças. Os maridos, mesmo numa postura de maior inibição, puderam expor-se e desnudar-se quanto às dores provocadas pelos insucessos dos tratamentos ou quanto à aposta na eficácia dos mesmos, como aconteceu com o Marido III. Um fato importante ao referir sobre a delicadeza em se falar deste tema, pelo fato de conter emoções e lembrança fortes, foi que o Marido I chegou a comentar para a sua esposa que "apesar da dificuldade e tristeza em ter relembrado todas as doloridas experiências, depois percebeu que foi dando um grande alívio[...]", o que sugere a importância de se compreender mais as vivências e de oferecer escuta para estes casais que injetam tanto investimento diante da realização do filho biológico tão desejado.

\section{Impactos dos tratamentos inexitosos na vida dos casais}

No tocante ao impacto que os tratamentos inexitosos geraram para a vida dos casais, 3 dimensões 
foram ressaltadas: a sexualidade, a comunicação e o orçamento doméstico. Sabe-se que estas 3 esferas são indissociáveis, mas serão dispostas separadamente para efeitos didáticos.

O impacto na sexualidade emergiu sob diferentes aspectos: questionamento quanto à utilidade do sexo; vivência da sexualidade do casal ficou em stand-by; o desaparecimento da libido; e a oscilação na frequência do sexo, que passou por diferentes momentos. Importante dizer que os impactos dos tratamentos inexitosos sobre a sexualidade foram citados apenas pelas mulheres, sendo que os homens nada relataram sobre a sexualidade do casal durante as tentativas inexitosas.

Sobre a sexualidade, a Esposa I relatou que, após as perdas, passou a questionar-se sobre a utilidade do sexo, uma vez que a gravidez não acontecia, fazendo com que "[...] eu não ligasse mais para o sexo". De acordo com Farinati (1996), na infertilidade estaria a origem de importantes problemas de ordem psicológica, provocando distúrbios na sexualidade. Faria et al. (2010) afirmam que o sexo pode tornar-se tarefa, dissociando-se do prazer, e pode haver uma diminuição na frequência sexual. Estes autores ainda pontuam que a alteração da sexualidade está diretamente relacionada com o êxito do tratamento de infertilidade. Melamed e Serger (2009) sugerem que "a infertilidade pode ser um fator iniciante, agravante ou perpetuador de uma disfunção sexual" (p. 63). As disfunções sexuais, por sua vez, dificultam e impedem que os casais tenham melhor qualidade de vida, e associam-se à questões psicológicas importantes que não podem ser minimizadas. Corroborando a ideia acima, Stevenson e Elliott (2011) afirmam que as disfunções sexuais são extremamente comórbidas com muitas doenças, traumas físicos e emocionais. Além disso, podem constituir efeitos colaterais frequentes e frustrantes sob o uso de medicamentos ou outros tratamentos médicos.

No período em que "digeria" o que estava acontecendo, a Esposa I lembrou ter ficado sem libido e percebeu que a "libido sumiu" após ter sido submetida à FIV. Ainda, de acordo com ela, o tratamento também a deixou "muito inchada". Entretanto, afirmou ter sido um período que o marido "respeitou, entendeu e não forçava a barra".

A Esposa II relatou que depois da última tentativa frustrada, que foi o quarto ciclo, "a relação teve um pouco de abalo, o relacionamento foi posto em cheque, a sexualidade ficou em stand-by". A reação stand-by, como afirma Justo, Melo e Faria (2010), é uma forma momentânea para evitar o contato com as situações emocionais mais dolorosas. Para Stevenson e Elliott (2011), “o impacto dos problemas sexuais sobre os pacientes e seus parceiros pode variar, desde embaraço, infelicidade e frustração até uma perda mais intensa da autoestima, que afeta a satisfação e a viabilidade do relacionamento" (p. 297).

No entanto, a Esposa III afirmou não ter havido interferência no relacionamento (afetivo e sexual), achou fácil e o casal cooperou uma vez que a sexualidade já era ativa, fato também confirmado por seu marido. Vale observar que o Casal III estava com aproximadamente um ano e meio no acompanhamento especializado para fertilidade, na fase inicial do tratamento, fazendo exames para avaliação diagnóstica e havia passado por dois ciclos de indução de ovulação. Estudos apontam para a importância do tempo de tratamento dos ciclos de repetição contribuindo para o comprometimento na relação (Chiba et al., 1997; Filetto \& Makuch, 2005; Sydsjo et al., 2005).

Relativo ao impacto na esfera comunicacional, o estado de limite pode ser ilustrado na seguinte fala: "Mas a gente estava muito no limite: psicológico, daqueles exames, daquelas injeções [...]. Estava muito difícil. E a gente tava unido, bem unido" (Esposa II, referindo-se à vivência durante o quarto ciclo e terceira perda). Neste mesmo período ela percebeu que o marido viveu um momento de intensa introspecção: "Ele se fechou", situação também confirmada pelo esposo. As comunicações "constituem-se em relação, operando sempre, e necessariamente, por circularidade, 
mesmo quando uma das partes se retrai, se cala e se afasta" (Anton, 2000, p. 77).

A respeito do comportamento dos homens em situações difíceis, tal qual ilustrado acima pela Esposa II, Silva e Lopes (2011), apresentam estudos que descrevem que um comportamento comum é a dificuldade em expressar os sentimentos em momentos de crise e que eles mantêm o distanciamento emocional das parceiras. Outros autores destacam que o tratamento é exigente, tanto para as mulheres como para os homens, embora de maneiras diferentes. Se o tratamento não for bem sucedido, o casal enfrenta novas decisões, como se deve ou não realizar um segundo ou terceiro tratamento. Essas decisões exigem habilidade na comunicação e na tomada de decisões dentro do relacionamento e podem causar estresse e tensão entre o casal (Corrêa et al., 2007; Muñoz, 2006; Sydsjo et al., 2005).

Um fato marcante relembrado pela Esposa I, relativo ao impacto das tentativas inexitosas sobre o relacionamento, foi a ocorrência de um afastamento emocional entre o casal, refletido na falta de diálogo e também na inexistência de sexo. Justo et al. (2010) afirmam que no funcionamento psicológico do casal, incidem sobre eles consequências negativas exercidas pelo estado de infertilidade e pelas exigências da reprodução medicamente assistida, levando-os a um processo de adaptação. Neste sentido, é comum encontrar uma postura de inibição dos cônjuges, refletidos na comunicação emocional, mas também podendo ser estendido para a intimidade sexual.

A Esposa III afirmou que aproximadamente 8 dias após o ciclo da indução, era um período em que ficava ansiosa e na certeza de que estava grávida, ocasionando grande decepção quando o exame constatava um resultado negativo. Tal resultado era fonte de frustração, reclamações, lamentação e irritação com o marido. Em pesquisa sobre os mecanismos de defesa de casais inférteis e casais férteis, constatou-se a tendência dos casais inférteis expressarem impulsos de agressividade, direcionando ou projetando o ataque sobre o objeto frustrante (Justo et al., 2010). Os autores acrescentam que esses casais podem apresentar níveis mais elevados de mecanismos de defesa, que podem se manifestar através da intelectualização e da negação de situações frustrantes.

Ao descrever sua última perda, segundo aborto após início do tratamento, a Esposa III revelou que, embora tenha sido menos sofrido que os abortos anteriores (houve um aborto espontâneo durante o namoro e um aborto logo no início dos tratamentos), o apoio total recebido pelo marido fez com que decidisse não se separar. Neste sentido, Makuch e Filetto (2010) afirmam que a presença e apoio recebidos pelos parceiros durante o tratamento é considerado importante. O companheirismo dos maridos destaca-se nesses momentos, representando um período com desafios em termos de continuidade do vínculo conjugal (Silva \& Lopes, 2011).

Conforme os relatos, no tocante à comunicação, os diferentes procedimentos vivenciados pelos casais desencadearam estados emocionais que afetaram o processo comunicacional conjugal. O período de silêncio vivenciado pelos casais I e II após as perdas, a compreensão do Marido I durante o período de libido reduzida da esposa, a introspecção do Marido II, os estados emocionais intensos vivenciados pela Esposa III após os resultados negativos dos ciclos de indução de ovulação, todos representam recursos pessoais e conjugais que manifestaram espanto, decepção, dor, dificuldade de lidar com uma surpresa indesejada, agressividade, raiva, compreensão, apoio. Todas essas reações são recursos que funcionam enquanto técnicas comunicacionais utilizadas pelas pessoas, e são vistas como "indicadores seguros do funcionamento interpessoal" (Satir, 1993, p. 107).

O estado de saúde pode ser representado pelo modo como as pessoas são capazes de utilizar adequadamente seus recursos de comunicação (verbal e não verbal) para enfrentar e resolver as dificuldades que surgem no curso da vida (Walsh, 2002). 
No complexo processo de comunicação humana estão os "acontecimentos ligados aos comportamentos, manifestos ou latentes" (Miermont, 1994, p. 439) que podem descrever uma comunicação efetiva e acurada manifesta através de expressões de sentimentos positivos, elogios, agrados, opiniões, desejos e escuta ativa, mas também, demonstram a deficiência na comunicação que pode ser uma fonte geradora de outros conflitos (Figueredo, 2005). Esses casais apresentaram variados recursos na tentativa de lidar com inúmeras emoções suscitadas pelos diferentes tratamentos e suas etapas.

Quanto ao orçamento doméstico, os casais não referiram grande impacto negativo de modo que interferisse significativamente na dinâmica financeira, embora tivessem mencionado que os procedimentos foram bastante caros. Este fato diferencia-se do encontrado na literatura que tende a apontar a questão financeira como um dos principais fatores responsáveis pela desistência e/ou abandono dos tratamentos. O Casal I referiu que, apesar de ter investido grandes valores, não chegou a influenciar no seu estilo de vida. Igualmente para o Marido II que revelou que os procedimentos dos tratamentos de reprodução assistida foram muito onerosos: "Raspamos o que tínhamos na poupança e nos descaptalizamos". Porém, este não interferiu na qualidade de vida do casal, fato confirmado por sua esposa. É importante observar que todos os cônjuges dos Casais I e II eram funcionários públicos (municipais e estaduais, respectivamente). Contudo, vale pontuar que mesmo não tendo interferido na qualidade ou estilo de vida, ambos relataram os altos custos financeiros associados ao tratamento como um todo. O Casal III, usuário do sistema público, não referiu ônus dos tratamentos efetuados até o momento em que a entrevista foi efetuada.

Neste sentido, Faria et al. (2012) apresentam um estudo, na cidade de Santiago, com 160 pacientes, parte usuária de tratamentos em hospitais públicos, e outra parte em hospitais privados.
Todos relataram sobre o problema que os custos do tratamento para infertilidade representava para eles e da necessidade de trabalhar mais para custeá-los. Deste modo, as autoras atentam para o fato das técnicas utilizadas serem dispendiosas e poderem tornar-se, ao longo do tratamento, fatores de preocupação e fontes geradoras de sentimentos negativos, como ansiedade e tristeza, variando de acordo com o poder econômico e equilíbrio emocional de cada casal.

Embora não referindo impacto financeiro que afetasse significativamente a qualidade de vida do casal, a Esposa I destacou que precisaram fazer "um intervalo entre o tratamento de indução, que era barato, e a inseminação artificial que era cara". Na época estavam construindo sua casa e precisaram priorizar a finalização da construção, para somente depois se prepararem para um novo tratamento. Esse período transcorreu num intervalo de dois anos, o que implicou no aumento da idade de ambos os cônjuges. Esse fato foi também confirmado pelo marido, que chegou a questionar-se quanto ao tempo que levaram para juntar o dinheiro e o tempo que o tratamento levou para ser efetuado e não ter gerado a gravidez esperada.

Até o momento da entrevista, o Casal III não mostrou preocupação quanto aos gastos financeiros e interferência no orçamento doméstico, e puderam pagar os exames solicitados até então. Mesmo sendo usuários do tratamento de reprodução assistida pelo Sistema Único de Saúde, a procura pelas clínicas privadas deu-se para efetuarem os exames com mais rapidez. Isso ocorreu devido às greves que estavam ocorrendo no mesmo período e poderia acarretar na demora para realizá-los, e com isso comprometer o tratamento. É importante observar, como anteriormente citado, que a demora num tratamento de reprodução assistida não é recomendável, devido às várias implicações que isso pode acarretar (Gradvohl et al., 2013; Oriá \& Ximenes, 2004; Van der Poel, 2012).

Os fatores geralmente associados ao aspecto financeiro relativos à dificuldade de custeio dos 
tratamentos refletindo em desistência e/ou abandono e ônus interferindo na qualidade de vida familiar não foram registrados pelos casais entrevistados, embora os Casais I e II tenham mencionado a descapitalização de reservas como poupança, ou mesmo, no tempo necessário para reunirem o dinheiro para custear o tratamento. Mesmo o casal usuário do Sistema Único de Saúde não citou qualquer queixa sobre dificuldades dessa ordem.

\section{Considerações finais}

$\mathrm{O}$ artigo buscou compreender as vivências de casais inférteis diante de tentativas inexitosas de reprodução assistida. Mais especificamente, procurou descrever os sentimentos mais frequentes diante das múltiplas tentativas inexitosas, e os possíveis impactos destas tentativas nas diferentes dimensões da vida dos casais entrevistados.

A análise das entrevistas evidenciou que a repetição dos tratamentos influenciou no aumento do sofrimento dos cônjuges e ocorreu um forte investimento subjetivo para a chegada do filho, que implicou tempo, dinheiro, disciplina, persistência, expectativa, ansiedade e sofrimento de cada cônjuge (em maior ou menor grau). Também ficou bastante evidenciado nas entrevistas que a lembrança dos tratamentos continuava a mobilizar forte conteúdo emocional no casal durante as entrevistas, sobretudo porque estes casais perceberam que, nem mesmo o grande desejo de terem seus filhos e as reiteradas tentativas de reprodução assistida, foram suficientemente capazes de gerar os filhos biológicos que tanto almejavam.

Neste estudo, dos 3 casais pesquisados, 2 deles se submeteram à variadas técnicas de reprodução assistida sem sucesso, e desistiram em dar continuidade após a terceira tentativa ineficaz. O terceiro casal ainda encontrava-se em fase inicial de diagnóstico e tratamentos, fato que justifica darem continuidade. No que se refere à quantidade de tentativas que se leva à desistência ou abandono, bem como ao desgaste sofrido pelos casais, os dados da pesquisa foram condizentes aos de outros trabalhos. Os estudos de Sydsjo et al. (2005), por exemplo, revelaram que os comprometimentos tendem a aparecer após 3 ciclos de tratamento sem sucesso. Filetto e Makuch (2005) sugerem que o estresse e a frustração podem ser ocasionados após o quarto ciclo e Chiba et al. (1997) consideram que o potencial prejuízo pode ocorrer num período acima de 4 anos de tentativas do tratamento. Entre os casais desta pesquisa, aqueles que desistiram ou interromperam, tentaram durante um período de 1 ano e meio a 2 anos, e foram submetidos a uma média de 4 ciclos, para então seguirem com outras alternativas ao tratamento. O Casal III que não havia interrompido o tratamento ou escolhido outras alternativas, ainda encontrava-se na fase diagnóstica e fora submetido ao ciclo de indução por 2 vezes, não constituindo ainda a média confirmada pela literatura.

No presente estudo, a desistência esteve associada às particularidades da história dos casais. No entanto, a dor emocional devido à sucessão de tratamentos sem êxito, foi mencionada por todos, e representou um forte motivador para a desistência, coincidindo com a literatura. Embora o fator financeiro tenha sido citado como importante, não se constituiu como o principal motivo para a desistência dos tratamentos. Esse fato diferencia-se dos achados na literatura, uma vez que o fator financeiro é considerado no Brasil um forte motivador para desistência do tratamento de reprodução assistida (Filetto \& Makuch, 2005). Uma das explicações pode estar associada ao fato de que, em 2 casais, todos os cônjuges tinham carreiras estáveis através de concursos públicos, fato que os permitiu fazer um planejamento e preparação para os ciclos de maiores custos, sem que interferisse na qualidade de vida. Sobre o casal usuário do SUS, verificou-se que pôde custear por conta própria os exames e remédios.

A decisão pelo início dos tratamentos foi motivada por um dos cônjuges e apoiada pelo/a companheiro/a. A desistência ou a continuidade, assim 
como a escolha por outra alternativa, deu-se da mesma forma, mostrando forte vínculo da relação. Os casais permaneceram unidos durante todo o processo de tratamento, durante as decisões em dar seguimento ou não às etapas seguintes, depois da desistência/interrupção, e cumprindo outros planos, inclusive no exercício da parentalidade adotiva. A importância do vínculo conjugal em casais inférteis é apontada por outros trabalhos (Lopes \& Pinto, 2012; Silva \& Lopes, 2009).

Dos 3 casais, aquele que não havia desistido dos tratamentos e a esposa rejeitava outras possibilidades, encontrava-se na fase diagnóstica e havia feito apenas os ciclos de indução de ovulação, considerados de baixa complexidade e menos invasivos. Não pensar em outras estratégias, para esta esposa, talvez estivesse ainda associado ao fato de não ter experimentado técnicas mais complexas e invasivas, assim como não ter vivenciado um número maior de repetições inexitosas. Esse dado é corroborado pela literatura que aponta que, nas primeiras tentativas, provavelmente por estarem com altas expectativas de sucesso, as mulheres tendem a minimizar o desconforto e o impacto da medicação no organismo (Makuch \& Filetto, 2010). Em seguida, conforme a complexidade dos tratamentos aumenta e ocorre o acúmulo de vivências de resultados sem êxito, a chance do casal optar pela desistência do tratamento -como uma forma de evitar mais sofrimentos- aumenta.

No campo da infertilidade e dos tratamentos de reprodução assistida, mesmo que a tecnologia tenha propiciado possibilidade para a realização do filho biológico tão desejado, é preciso também considerar o sofrimento que as inúmeras tentativas inexitosas podem representar para a vida de muitos casais. Acredita-se que grande parte do sofrimento pessoal e conjugal poderia ser evitado, se houvesse maior investimento para o acompanhamento mais contínuo destes casais durante os tratamentos. Tal acompanhamento, dentre outras temáticas, deveria enfocar as limitações das técnicas de reprodução assistida, bem como a existência de outras formas de vivência da maternidade/paternidade.

Entende-se que foi de fundamental importância que as entrevistas ocorressem com os cônjuges, separadamente, uma vez que possibilitou espaço para que as individualidades se manifestassem. Durantes a análise dos dados, no entanto, optou-se por uma descrição que considerasse os pontos comuns/semelhanças entre as respostas dos diferentes membros da díade e entre os casais, assim como das particularidades de cada casal.

Em termos de sugestões, sugere-se que estudos futuros possam focar no aumento da amostra (já que nesse estudo teve-se apenas 3 casais), mantendo como critério de inclusão casais com 3 tentativas inexitosas (tal como recomendado pela literatura), e que tenham passado pelo mesmo tipo de tratamento (e.g. indução de ovulação ou FIV), uma vez que as técnicas provocam efeitos emocionais diversos. Sugere-se, ainda, a realização de pesquisas com casais em grupos; a utilização de outros instrumentos com os participantes (genograma ou outros instrumentos relacionados à satisfação conjugal, por exemplo); o acompanhamento longitudinal dos casais, sobretudo daqueles que continuam tentando engravidar via reprodução assistida, apesar das vivências das repetidas falhas dos tratamentos; assim como a realização de pesquisas que enfoquem os arranjos conjugais formados por casais do mesmo sexo, dado que a ênfase dos estudos sobre reprodução assistida tende a ser sobre os casais heterossexuais.

Por fim, espera-se que esse estudo possa trazer contribuições ao campo dos estudos da conjugalidade de casais inférteis que se submetem às técnicas de reprodução assistida e que não obtém êxito nas suas múltiplas tentativas. $\mathrm{O}$ estudo das vivências emocionais e impactos dos tratamentos inexitosos na vida dos casais com esse perfil, sublinha a importância do apoio psicológico (antes, durante e após a realização dos ciclos), assim como de práticas biomédicas e psicológicas que visem ao 
bem-estar dos pacientes. Tais práticas devem prezar pelo respeito às subjetividades (sonhos, desejos, possibilidades e limitações -físicas, psicológicas, financeiras e socioculturais) de cada casal e nunca sobrepor os interesses mercadológicos e financeiros aos primeiros. Por fim, esse estudo reitera a importância de se considerar como única a experiência de cada casal infértil que, no afã de realizar o sonho da maternidade/paternidade, percorre a saga dos tratamentos de reprodução assistida.

\section{Referências}

Anton, I. L. C. (2000). Contribuições oriundas da moderna teoria das comunicações. Em A escolha do cônjuge: um entendimento sistêmico e psicodinâmico (pp. 71-79). Porto Alegre: Artes Médicas.

Arruda, C. P. \& Lima, M. T. A. (2012). O fruto inatingível: uma análise simbólica da infertilidade masculina. O Mundo da Saúde, 36(2), 284-290.

Borsa, J. C. \& Nunes, M. L. T. (2011). Aspectos psicossociais da parentalidade: o papel de homens e mulheres na família nuclear. Psicologia Argumento, 29(64), 31-39.

Carter, B. \& McGoldrik, M. (1995). As mudanças no ciclo de vida familiar: uma estrutura para a terapia familiar. Em B. Carter \& M. McGoldrik (orgs.), As mudanças no ciclo de vida familiar: uma estrutura para a terapia familiar (pp. 7-29). Porto Alegre: Artes Médicas.

Chiba, H., Mori, E., Morioka, Y., Kashiwakura, M., Nadaoka, T., Saito, H. \& Hiroi, M. (1997). Stress of female infertility: relations to lenght of treatment. Gynecology obstetric investigation, 43(3), 171-177.

Conselho Federal de Medicina - CFM- (2013). Resolução Federal Brasileira de Reprodução Assistida. Resolução CFM n ${ }^{\circ}$ 1.957/2010, D.O.U. Mai/13, Seção I, 119.

Conselho Nacional de Saúde - CFM- (2012). Resolução do Conselho Nacional de Saúde de Testes e Pesquisas com Seres Humanos. Resolução CNS n 466/2012, D. O. U. Jun/13, Seção I, 59. Corrêa, K. R. F., Vizzotto, M. M. \& Cury, A. F. (2007). Avaliação da eficácia adaptativa de mulheres e homens inseridos num programa de fertilização in vitro. Psicologia em Estudos, 12(2), 363-370.

Faria, D. E. P., Grieco, S. C. \& Barros, S. M. O. (2012). Efeitos da infertilidade no relacionamento dos cônjuges. Revista da Escola de Enfermagem, 46(4), 794-801.

Farinati D. M. (1996). Aspectos emocionais da infertilidade e da reprodução medicamente assistida (dissertação de mestrado). PUCRS, Porto Alegre, Brasil.

Farinati, D. M., Rigoni, M. S. \& Müller, M. C. (2006). Infertilidade: um novo campo da psicologia da saúde. Estudos de Psicologia (Campinas), 23(4), 433-439.

Figueredo, P. M. V. (2005). A influência do lócus de controle conjugal, das habilidades sociais conjugais e da comunicação conjugal na satisfação com o casamento. Ciências \& Cognição, 6(1), 123-132.

Filetto, J. N. \& Makuch, M. Y. (2005). Long-term follow-up of women and men after unsuccessful IVF. Reproductive biomedicine online, 11(4), 458-463.

Gameiro, S., Silva, S. \& Canavarro, M.C. (2008). A experiência masculina de infertilidade e de reprodução medicamente assistida. Psicologia, Saúde \& Doenças, 9(2), 253-270.

Gorayeb, R., Borsari, A. C. T., Gomes, A. C. R., Romão, A. P. M. S. \& Shuhama, R. (2009). Caracterização clínica e psicossocial da clientela de um ambulatório de esterilidade. Estudos de psicologia, 26(3), 287-296.

Gradvohl, S. M. O., Osis, M. J. D. \& Makuch, M. Y. (2013). Características de homens e mulheres que buscam tratamento para infertilidade em serviço público de saúde. Reprodução \& Climatério, 28(1), 18-23.

Justo, J. M. R. M., Melo, V. A. L. C. \& Faria, A. S. (2010). Defence mechanisms of infertile couples 
vs. fertile couples. International Journal of Developmental and Educational Psychology, 1(2), 433-442.

Lopes, V. \& Pinto, G. (2012). Quando a gravidez não acontece: intervenção psicológica na infertilidade. Em M. J. Correia (org.), A psicologia na saúde da mulher e da criança: intervenções, práticas e contextos numa maternidade (pp. 36-47). Lisboa: Placebo Editora.

Makuch, M. Y. \& Filetto, J. N. (2010). Procedimentos de fertilização in vitro: experiência de mulheres e homens. Psicologia em estudo, 15(4), 771-770.

Melamed, R. M. \& Seger, L. (2009). Infertilidade e sexualidade. Em R. M. Melamed, L. Seger \& E. Borges Jr. (orgs.), Psicologia e reprodução humana assistida: uma abordagem multidisciplinar (pp. 60-64). São Paulo: Santos.

Miermont, J. \& Cols. (1994). Dicionários de terapias familiares: teoria e prática. Porto Alegre: Artes Médicas.

Monteiro, C. F. A. \& Teixeira, L. C. (2011). Família e tecnologias reprodutivas: considerações sobre a transmissão psíquica geracional. Arquivos Brasileiros de Psicologia, 63(2), 92-101.

Moura, M. D., Souza, M. C. B. \& Scheffer, B.B. (2009). Reprodução assistida: um pouco de história. Revista da Sociedade Brasileira de Psicologia Hospitalar, 12(2), 23-42.

Muñoz, L. M. P. (2006). Infertilidad y pareja: construcciones narrativas como horizonte para la intervención. Diversitas - Perspectivas en Psicología, 2(1), 149-158.

Oriá, M. O. B. \& Ximenes, L. B. (2004). Casais inférteis diante da fertilização in vitro: o significado de vivenciar essa decisão. Acta Paulista de Enfermagem, 17(3), 278-285.
Satir. V. (1993). Terapia do grupo familiar. Rio de Janeiro: F. Alves.

Silva, I. M. \& Lopes, R. C. S. (2011). Relação conjugal no contexto de reprodução assistida: o tratamento e a gravidez. Psicologia: Teoria Pesquisa, 27(4), 449-457.

Stevenson, R. W. D. \& Elliott, S. L. (2011). Sexualidade e doença. Em S. R. Leiblum (org.), Princípios e práticas da terapia sexual (pp. 295-330). São Paulo: Roca.

Sydsjo, G., Ekholm, K., Wadsby, M., Kjellberg, S. \& Sydsjo, A. (2005). Relationships in couples after IVF treatment: a prospective follow-up study. Human reproduction, 20(7), 1952-1957.

Van der Poel, S. Z. (2012). Historical walk: the HRP special programme and infertility. Gynecologic and obstetric investigation, 74(3), 218-227.

Vargas, E. P. \& Moás, L. D. C. (2010). Discursos normativos sobre o desejo de ter filhos. Revista da Saúde Pública, 44(4), 758-762.

Ventura, M. M. (2007). O estudo de caso como modalidade de pesquisa. Revista da SOCERJ, 20(5), 383-386.

Verberg, M. F. G., Eijkemans, M. J.C., Heijnen, E. M. E. W., Broekmans, C. de Klerk, B. C. J. M. Fauser \& N. S. Macklon (2008). Por que os casais abandonam o tratamento de fertilização in vitro? Um estudo prospectivo de estudo de coorte. Reprodução Humana, 23(9), 2050-2055.

Walsh, F. (2002). Casais saudáveis e casais disfuncionais: qual a diferença? Em M. Andolfi (org.), A crise do casal: uma perspectiva sistêmico-relacional (pp. 13-28). Porto Alegre: Artmed.

Yin, R. K. (2010). Estudo de caso: planejamento de método. Porto Alegre: Bookmann. 